\title{
HoMEcare aRm rehabiLItatioN (MERLIN): preliminary evidence of long term effects of telerehabilitation using an unactuated training device on upper limb function after stroke
}

\author{
Samantha G. Rozevink* (1), Corry K. van der Sluis and Juha M. Hijmans
}

\begin{abstract}
Background: While short term effects on upper limb function of stroke patients after training with robotic devices have been studied extensively, long term effects are often not addressed. HoMEcare aRm rehabiLItatioN (MERLIN) is a combination of an unactuated training device using serious games and a telerehabilitation platform in the patient's home situation. Short term effects showed that upper limb function improved after training with MERLIN. The aim was to determine long term effects on upper limb function and quality of life.

Methods: Six months after cessation of the 6 week MERLIN training program, the upper limb function and quality of life of 11 chronic stroke patients were assessed. Upper limb function was measured using the Wolf Motor Function Test (WMFT), Action Research Arm Test (ARAT) and Fugl-Meyer Assessment-Upper Extremity (FMA-UE). EuroQoL-5D (EQ-5D) was used to measure quality of life.

Results: The WMFT, ARAT and EQ-5D did not show significant differences 6 months after the training period compared to directly after training. At 6 months follow-up, FMA-UE results were significantly better than at baseline. Time plots showed a decreasing trend in all tests.

Conclusion: Training effects were still present at 6 months follow-up, since arm function seemed similar to directly after training and FMA-UE results were better than at baseline. However, because of the decreasing trend shown in all tests, it is questionable if improvements will be maintained longer than 6 months. Due to the sample size and study design, results should be interpreted with caution.

Trial registration This study is registered at the Netherlands Trial Register (NL7535). Registered 18-02-2019, https://www. trialregister.nl/trial/7535
\end{abstract}

Keywords: Stroke, Rehabilitation, Telerehabilitation, Home training, Upper limb, Hand, Training device, Task specific, Serious games

*Correspondence: s.g.rozevink@umcg.nl

University of Groningen, University Medical Center Groningen, Department of Rehabilitation Medicine, PO Box 30001, 9700

RB Groningen, The Netherlands

\section{Introduction}

The majority of people who suffered a stroke have persistent problems with using the arm or hand in daily life, with estimates between 62 and $88 \%$ [1,2]. After a severe paresis, only $7-18 \%$ regains full function of the original author(s) and the source, provide a link to the Creative Commons licence, and indicate if changes were made. The images or other third party material in this article are included in the article's Creative Commons licence, unless indicated otherwise in a credit line to the material. If material is not included in the article's Creative Commons licence and your intended use is not permitted by statutory regulation or exceeds the permitted use, you will need to obtain permission directly from the copyright holder. To view a copy of this licence, visit http://creativecommons.org/licenses/by/4.0/. The Creative Commons Public Domain Dedication waiver (http://creativeco mmons.org/publicdomain/zero/1.0/) applies to the data made available in this article, unless otherwise stated in a credit line to the data. 
upper limb [1,3]. Actual numbers might be less drastic since these studies are rather dated and specific groups of severely affected stroke patients were investigated. Nevertheless, the latest insights show that improvement of the upper limb function is possible even 1 year after stroke onset $[4,5]$. More training possibilities have become available for patients in the chronic phase of stroke. Patients with a better upper limb function may be more independent and less reliant on their caregivers, which is important for a stroke survivor [6]. An improved arm function could also lead to more use of the arm in daily life which in turn is beneficial for further recovery. Additionally, independence of the patient may unburden the health care system due to a lower need for care and adaptations at home or a reduction in the need for long term therapy. More frequent, intensive or longer training programs have been positively correlated with improvement in upper limb function [7]. Many patients would like to receive more training than they are currently offered, unfortunately this is not possible in all instances due to limited healthcare resources [6]. The search for alternative ways to provide therapy is on-going.

A promising solution is to use (robotic) devices to train the upper limb using serious games. Several reviews revealed that robotic training is safe and can provide more intensive training than in standard care situations, especially in the chronic phase [8-10]. Robotic training devices seem to improve the upper limb function directly after training [11, 12]. While these are only short term effects, equally important is to know whether training with these devices results in long lasting improvements. In only one review the follow-up after training was described, and the authors concluded that there was no significant difference between a robotic training group and the conventional group when matched for training intensity [8]. This conclusion was based on a meta-analysis using data from only three papers in which two investigated a robotic device and one a non-robotic device $[8$, 13-15]. Evidently, insufficient information is yet available on the long term effects of training with (non)robotic devices.

We investigated the long term effect of hoMEcare aRm rehabiLItatioN (MERLIN), an unactuated (nonrobotic) training device combined with a telecare platform to train the arm and hand at home (see Fig. 1). The short term results of MERLIN showed that moderately affected patients in the chronic phase of stroke were able to achieve a statistically significant as well as a clinically relevant improvement in upper limb function [16]. The improvements were retained at least 6 weeks after termination of the training. We expected patients to use the affected arm more in daily life after the intervention due to an improved arm function. Some evidence suggests

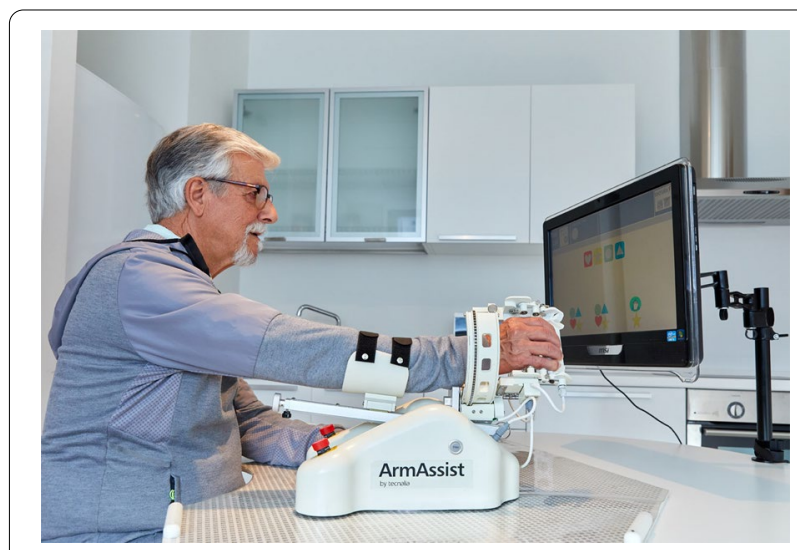

Fig. 1 hoMEcare aRm rehabiLItatioN system for training the upper limb function at home

that after intense therapy, patients are able to use the hand more during different activities with effects lasting up to 1 year $[17,18]$. Therefore we hypothesized that upper limb function would improve between cessation of the intervention and 6 months after the intervention. The aim of this study was to assess upper limb function and quality of life in patients in the chronic phase after stroke, who trained with MERLIN at home 6 months prior to the assessment. First we will discuss the difference between our findings directly after the training and the findings at 6 months follow-up. Thereafter, we compare the 6 month follow-up data to the data of all previous measurements.

\section{Methods}

\section{Subjects}

Patients in the chronic phase after a single stroke ( $>6$ months and $<3$ years) were eligible. Patients had to be able to extend their fingers, but Fugl-Meyer Assessment-Upper Extremity (FMA-UE) score had to be lower than 50. Extended inclusion and exclusion criteria were published elsewhere [16]. The study was approved by the local Medical Ethics Committee of the University Medical Center Groningen (UMCG) (METc 2019/189). All patients provided written informed consent before participating.

\section{Design}

Participants were measured repeatedly over the course of 9 months (see Fig. 2). Data gathered for this paper concerned measurements at 6 months follow-up which were added to the existing dataset. The long term measurement was not part of the original MERLIN grant proposal and was therefore considered as a separate study. Patients who participated in the previous part of the trial were invited via a phone call for the final follow-up 


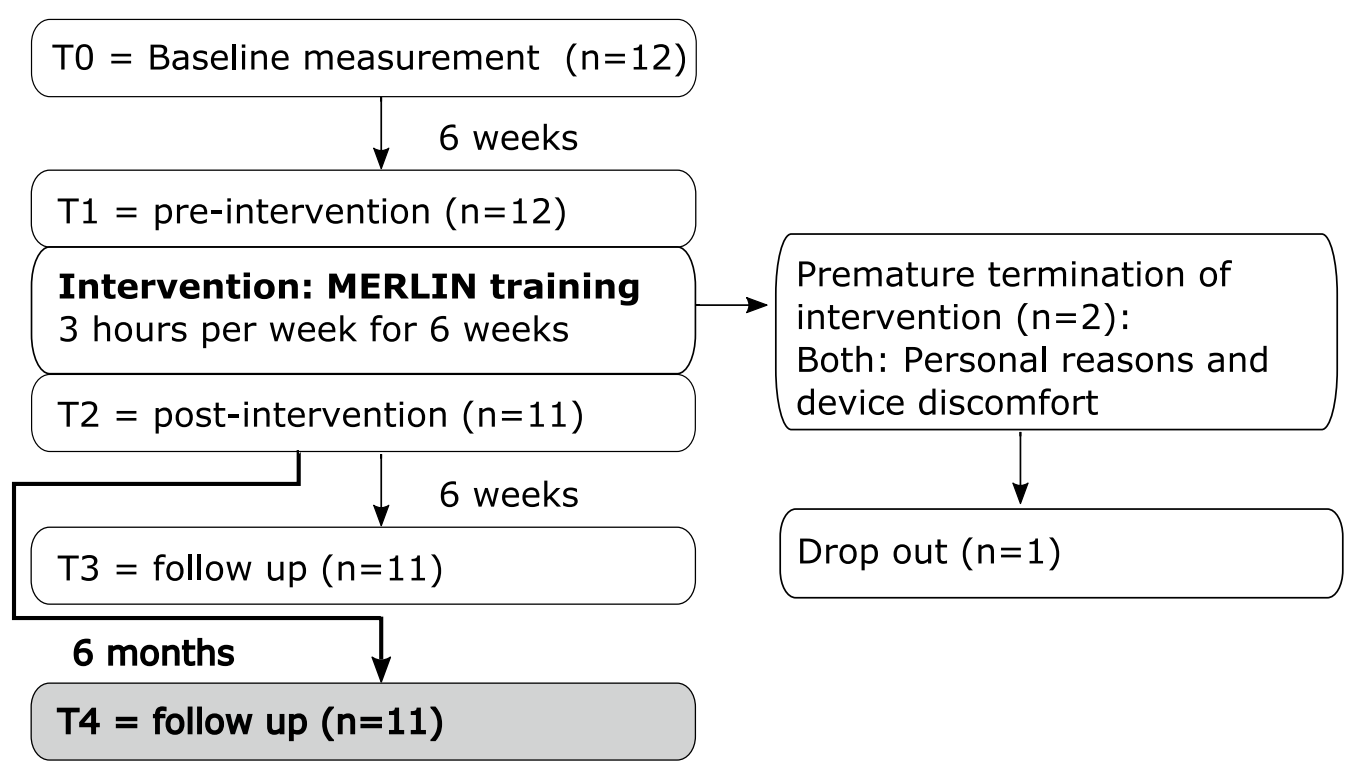

Fig. 2 Flow diagram of the study. $n=$ number of patients. Two patients terminated the intervention prematurely, of whom one still participated in remaining measurements T2, T3 and T4. Grey shade= measurement described in the current paper. All other measurements (white boxes) have been described in [16]

measurement. During the intervention period, one patient dropped out after 3 weeks and was unable to complete the post-intervention measurement (T2, see Fig. 2). Due to the short training time and the patient's fragility, she was excluded for further measurements. Another participant stopped training after 5 weeks, but was able and willing to continue the follow-up measurements. All T4 measurements of the eleven patients took place between May and November 2020.

\section{Intervention}

The details of the intervention were described previously [16], but main characteristics will be mentioned here as well. Participants received the MERLIN system at home, consisting of the ArmAssist device, laptop and placemat (the surface on which the ArmAssist was used). The ArmAssist is a low-cost unactuated device, which behaves similarly to a computer mouse. The ArmAssist was used to play serious games on a computer. In addition, it allowed the user to train several movements with the arm, wrist and hand. The laptop contained the telerehabilitation software and the serious games. Via the telerehabilitation platform the therapist was able to set the training games, monitor therapy compliance through the number of played games and send and receive messages from the patient.

The therapy provided was task specific of nature; intensive and repetitive, targets were presented randomly in the visual work space, visual feedback and positive reinforcement was provided [19]. A calibration procedure was performed every 2 weeks to adjust the system to the participant's capabilities to maintain a challenging environment. In the intervention period, participants were instructed to train with MERLIN 3 hours per week for 6 weeks, aiming at a total training time of at least $18 \mathrm{~h}$ [2]. Patients were able to determine their own training time and duration, although a minimum of $3 \mathrm{~h}$ per week was requested.

From T0 to T3, patients did not follow any other functional arm or hand therapy. However, between T3 and T4 they were allowed to resume their previous therapy or start new therapies.

\section{Outcomes}

Outcomes were based on the International classification of Functioning, Disability and Health to classify the patient's health state, based on body functioning, activities and participation [20]. Main outcomes were three upper limb function tests: FMA-UE from the body function domain, Wolf Motor Function Test (WMFT) and Action Research Arm Test (ARAT) from the activities domain. These three common tests are widely used in stroke research and will be briefly addressed below [21]. To cover the participation domain, the quality of life questionnaire EuroQoL-5D was used.

The primary outcome was the WMFT, which consists of two scores: the time score per item and the Functional Ability Scale (FAS) [22]. Per item the maximum score is 
$120 \mathrm{~s}$, with lower completion time indicating better performance. The FAS is a score between 0 and 5 to score the patient's movement on dexterity, fluency and speed, with a maximum of 75 points. The FMA-UE scores the upper limb function in four categories: shoulder, wrist, hand and speed/coordination [23]. Every movement is scored between 0 and 2, with 66 being the maximum score to indicate normal motor functioning. The ARAT contains the subscales grasp, grip, pinch and gross arm movement. The movements performed in the ARAT are scored on a four point scale $(0-3)$ with a maximum of 57 points [24].

In order to evaluate a long term improvement in the arm function of chronic stroke patients, the minimal clinically important difference (MCID) was taken into account for every arm function test. The MCID reflects scores that are considered clinically relevant to the patient. The MCID is $3-6$ points, $6-8$ points and 5.7 points for the WMFT, FMA-UE and ARAT, respectively [25-27].

The quality of life was measured using the EuroQoL$5 \mathrm{D}-5 \mathrm{~L}$, containing a visual analogue scale (VAS) and a questionnaire of five questions which can be combined to calculate a health state [28]. The MCID for the EQ-5D is 0.1 for the health state and 8.6 for the VAS [28].

\section{Measurements}

Measurements and training took place at the participant's home. An independent researcher was trained by

Table 1 Patient characteristics at baseline and consumed additional therapy between six weeks (T3) and 6 months (T4) after cessation of the intervention (T2) $(\mathrm{N}=11)$

\begin{tabular}{ll}
\hline & $\begin{array}{l}\text { Mean } \pm \text { standard } \\
\text { deviation }\end{array}$ \\
\hline Age (years) & $66.0 \pm 8.4$ \\
Time after stroke (months) & $22.5 \pm 9.7$ \\
\hline & N \\
\hline Sex (male/female) & $8 / 3$ \\
Type of stroke (haemorrhagic/ischemic) & $1 / 10$ \\
Dominant side (left/right) & $0 / 11$ \\
Affected side (left/right) & $7 / 4$ \\
Consumed additional therapy between T3-T4 & \\
Physiotherapy (arm and leg) & 3 \\
Fitness training & 2 \\
Yoga & 1 \\
Neurofeedback therapy & 1 \\
Dry needling & 1 \\
None & 2 \\
\hline
\end{tabular}

an occupational therapist to perform the arm function tests. Blinding of the independent researcher was not possible due to the design of the study.

\section{Statistical analyses}

REDCap (Research Electronic Data Capture) was used to manage the data, servers were hosted at UMCG [29, 30]. REDCap is a secure, web-based software platform designed to support data capture for research. IBM SPSS Statistics (version 23) was used to perform statistical analyses. Data from the previous trial (T0 (baseline, 6 weeks before intervention), T1 (pre intervention), T2 (post intervention) and T3 (6 weeks retention)) were used in addition to the data gathered in this study. Data was tested for normality using Shapiro-Wilk test and z-scores for skewness and kurtosis. For parametric testing, a repeated measures ANOVA with a Bonferroni correction for multiple measurements was used $($ alpha $=0.05)$. Effect sizes were calculated using partial eta squared $\left(\eta_{\mathrm{p}}{ }^{2}\right)$. Non-parametric Friedman tests were used if normality was not met. Pearson correlation coefficients were calculated to investigate possible confounding effects of training time on upper limb function at follow-up. Because of the small sample size, an analysis on the observed trends was added.

\section{Results}

Patients were allowed to resume any type of therapy if desired (Table 1). One patient suffered a second stroke, but no clinical rehabilitation was necessary after hospitalization.

Due to the COVID pandemic, the 6 month follow-up measurement of two patients had to be performed via an online video call. The measurement equipment was delivered at the patient's house and via the online video call the researcher instructed the patient during the measurements. Two assessors were online present to assess the scores and to reach consensus on the final scores. The T4 measurements of the other patients were performed physically, taking into account the necessary health precautions.

In this section we will present the findings related to the T4 measurements (see Fig. 3). Other findings shown in Fig. 3 can be found in Appendix 1 and have been discussed previously [16].

\section{Statistical effects}

Data was normally distributed and thus a parametric ANOVA was used for the analysis. For the primary outcome, the WMFT FAS, a significant main effect was found $\left(\mathrm{F}(4,40)=6.94, \mathrm{p}<0.001, \eta_{\mathrm{p}}{ }^{2}=0.4\right)$. Post hoc analysis showed that this difference could not be attributed to a difference between $\mathrm{T} 4$ and other measurements. 
Regarding the secondary outcomes, significant main effects for the FMA-UE $(\mathrm{F}(4,40)=15.02, \mathrm{p}<0.001$, $\left.\eta_{\mathrm{p}}{ }^{2}=0.6\right)$ and ARAT $\left(\mathrm{F}(4,40)=3.67, \mathrm{p}=0.012, \eta_{\mathrm{p}}{ }^{2}=0.27\right)$ were found. FMA-UE post hoc analysis showed a significant improvement of 5.5 points between T0 and T4 $(p=0.016)$. Post hoc analysis of ARAT did not yield any significant differences. No significant differences were found between the measurements in quality of life on the EQ-5D questionnaire scores $(\mathrm{F}(4,40)=1.92, \mathrm{p}=0.126)$ or on the VAS $(\mathrm{F}(4,40)=1.53, \mathrm{p}=0.211)$.

The mean training time was $16.4 \pm 7.7 \mathrm{~h}$. The training time did not seem to influence the results at follow-up. Pearson correlation calculations for training time and the differences in arm performance between $\mathrm{T} 2$ and $\mathrm{T} 4$ resulted in low and non-significant correlation coefficients for FMA-UE $(r=-0.161, p=0.637)$, WMFT $(\mathrm{r}=0.075, \mathrm{p}=0.826)$ and ARAT $(\mathrm{r}=-0.122, \mathrm{p}=0.721)$.

\section{Observed trends}

An observed trend in all performance tests was that patients' upper limb function seemed to decrease slightly from cessation of intervention to 6 months post intervention. However, this decrease was not statistically significant. Visual inspection on an individual level showed that patients either increased or decreased a few points on the arm function tests. A lot of variation in arm function scores could be observed between the patients (see Fig. 3).

\section{Discussion}

In this short report we present the results of a followup study 6 months after cessation of a home rehabilitation program using an unactuated training device. The
WMFT and ARAT did not show significant differences 6 months after the training period compared to previous measurements. This could indicate that arm function improvement, established after 6 weeks of MERLIN training, remained stable on the ICF activity level. Due to the small sample size, results can be seen as preliminary evidence and should be investigated further. A significant increase was found between $\mathrm{T} 0$ and $\mathrm{T} 4$ for the FMA-UE, which showed that the arm function was significantly better 6 months after the training compared to the baseline measurement. Visual inspection of the data however showed that over time a decreasing trend was observed in all tests. It is therefore questionable if improvements will be maintained after a longer follow-up time than the 6 months we took into account.

Contrary to our hypothesis, arm function did not increase over time. We expected that arm function would continue to improve after the intervention as a result of using the arm more during activities, based on data from constraint induced movement therapy (CIMT) $[17,18]$. Kwakkel et al. showed that after CIMT, patients increased their arm-hand activities, but not basic activities of daily living at long term follow up [18]. Waddell et al. showed that despite intensive training, patients did not change their use of the affected upper limb in daily life [31]. It seems that improved arm function does not always transfers to activities. We measured on all three ICF levels. The significant improvement compared to baseline in the FMA-UE scores suggests that patients improved on the ICF body function domain. WMFT, ARAT and EQ-5D did not improve compared to baseline, suggesting that the improvement in body functions did not transfer to improvements in activity or participation
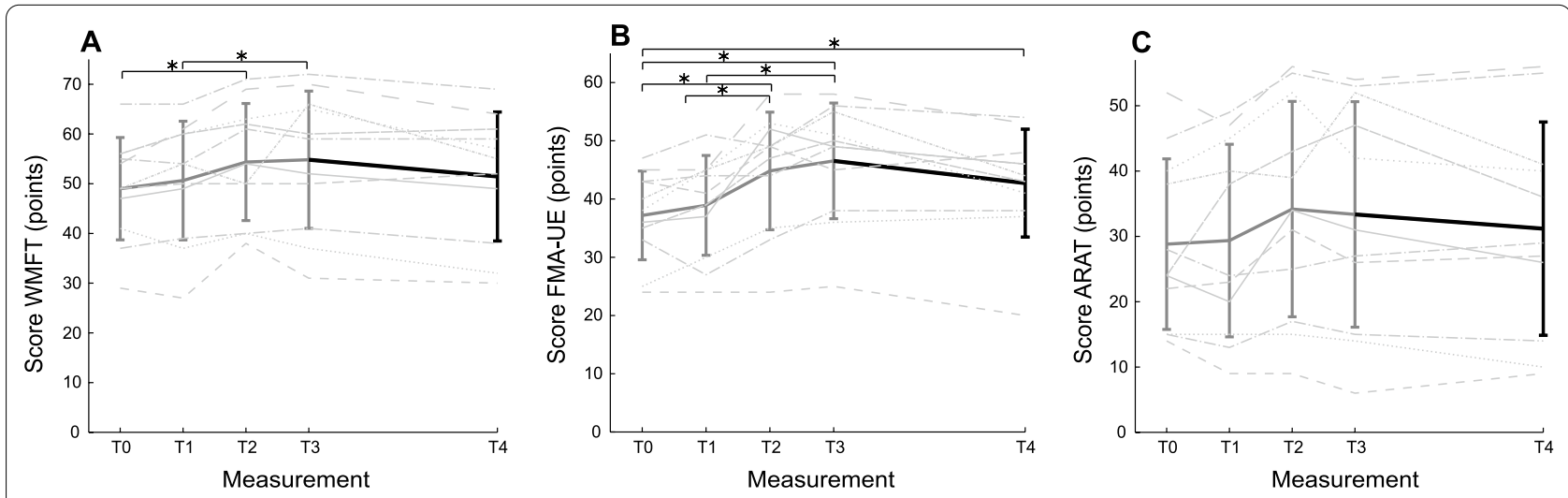

Fig. 3 Mean scores on the Wolf Motor Function Test (A), Fugl-Meyer Assessment - Upper Extremity (B) and Action Research Arm Test (C). ARATAction Research Arm Test; FMA-UEFugl-Meyer Assessment - Upper Extremity; WMFT Wolf Motor Function Test. T0 baseline; T1 pre-intervention; T2 post-intervention; T3 follow-up 6 weeks; T4 follow-up 6 months. Thick grey lines represent previous measurements; thick black lines represent the additional new data; light grey striped/dotted lines represent individual data. Vertical bars represent standard deviation. *Significant difference, $N=11$ 
level. Although clinically relevant improvements of the upper limb above the MCID were observed directly after training [16], these changes were insufficient to result in a relevant change on all ICF levels. Apparently the relation between MCID and performance on ICF levels needs further investigation. A non-significant positive correlation between training time and differences in arm performance between T2 and T4 was found for the WMFT. This positive correlation could indicate that patients who trained more hours deteriorated less over time. However for the FMA-UE and ARAT, the non-significant correlation was negative, which may reflect that patients who trained more hours, declined more in arm function. Measurements errors should be taken into account and the small sample size makes it difficult to draw conclusions regarding these correlations.

An explanation for the observed trend that arm function seems to be returning to baseline could be that, over time, patients stop using the affected arm/hand in daily life. They relapse into old behaviour of relative disuse of the affected arm in favour of the non-affected arm. Another reason could be that the transfer to daily activities of what is learned using a device is more difficult than when traditional training schemes are applied. Generalizability of training is known to be difficult in traditional rehabilitation [32]. How effects of device training can be generalized, has not been investigated yet.

The few studies that investigated long term results $(6$ months or longer) after the use of an assistive or robotic device reported long lasting improvement of the upper limb function. Housman et al. trained 14 chronic stroke patients with the non-robotic Therapy Wilmington Robotic Exoskeleton (T-WREX) [14]. After 6 months the upper limb function was still significantly better compared to baseline. Studies investigating the long term effect on upper limb function of robotic devices such as mirror image movement enabler (MIME) and MIT-Manus yielded similar results [15, 33]. Although the improvement in arm function was maintained over time, the absolute improvement in all three studies did not exceed the MCID on the FMA-UE, nor the minimal detectable change (MDC: 5.2 points [26, 34]). The MDC is a measure to account for "noise" in the scoring, improvement below the MDC could therefore also be attributed to measurement errors. The FMA-UE difference between $\mathrm{T} 0$ and $\mathrm{T} 4$ in the current study was 5.5 points, and thus larger than the MDC. The improvements from our and aforementioned studies are small and around the MDC, which means that outcomes may have been affected by measurement errors and therefore should be interpreted with caution. An explanation why our study was able to achieve significant improvement on the FMA-UE, above the noise level, could be the addition of the hand module. The T-WREX, MIME and MIT-Manus only train shoulder and elbow movements. The addition of wrist and finger movements makes MERLIN more versatile. The trends in our study showed that results on the shoulder and wrist part of the FMA-UE declined from T2 to T4, however the results obtained from the hand section seemed to remain constant. This may explain why improvement in FMA-UE score was larger in the MERLIN study than in the literature.

Breaking the habit of learned non-use is known to be difficult [35], which may also have been the case in our study. Similar effects have been shown in other therapy forms such as CIMT [18]. Motor function improvements remained stable compared to the start of the training, however effect size decreased over time [18]. One of the key points to maintain the improvement seems to be the dose of the training. Ward et al. showed that an intensive training of $90 \mathrm{~h}$ in 3 weeks resulted in longlasting improvements of 11 points on the FMA-UE after 6 months [36]. Although this study was not executed at the patients' home and not solely performed using training devices, it may open perspectives for intensive home training programs.

To maintain arm function levels after training, it could be interesting to investigate the effect of a repeated intervention program. Such an attempt has previously been made by Sale and colleagues: patients trained twice using the ReoGo robot device for 1 month, with 3 months in between [37]. At follow-up, 6 months after the second period of training, improvements in the Box and Block test and the Frenchay Arm Test appeared to be retained. FMA-UE scores returned to baseline during the 6 month follow-up. Apparently, this protocol is contradictory to our outcomes, since the ICF activity level was maintained while the body function was not. Future studies could investigate the effect of repeated periods of exercise more closely for a longer follow-up duration. Questions regarding the length of the exercise period and the time between exercise periods are of interest. Perhaps training programs of either high dose sessions from time to time or a continuous low dose of exercise are necessary to maintain the improved arm function.

Some limitations of the study have to be mentioned. Firstly, COVID-19 may have had an effect on the long term retention of the arm function. Due to COVID19 restrictions, patients may have been less challenged in engaging activities in daily life or in receiving additional therapies. Secondly, the small sample size of this study is a limitation. Due to limited availability of the 
devices and time restrictions of the initial project, only 12 patients were able to participate of whom 11 completed all measurements. Another limitation is the prepost-test design of the study. A randomized controlled trial may provide stronger evidence about the long term effects. Additionally, patients were able to resume other therapies after the T3 measurement. The therapies that were followed by the patients did not seem to have affected our outcomes since they were provided in a low dose (max twice a week) and none of the therapies focussed solely on the arm/hand function. Lastly, to conclude whether the arm function remained stable in the retention period, equivalence testing should have been used. However, this is not possible for within subject multiple measurements in a limited sample size. A large sample size is necessary to perform such tests. Therefore, we cannot conclude that the improved score after 6 weeks training is similar to the score after 6 months follow-up. We can only conclude that arm function did not significantly change during follow-up.

\section{Conclusion}

None of the arm function tests showed significant or clinical relevant differences in the period directly after cessation of the MERLIN intervention and 6 months later, indicating that the improved arm function did not change after cessation of the training. A significant improvement was found in the FMA-UE scores, indicating an improved arm function 6 months after training compared to baseline. Visual inspection of test results showed however a decreasing trend for all arm function tests between post-intervention and 6 months followup. It is questionable if the improvement in arm function found after the intervention will be maintained after a longer follow-up period. No differences were observed in quality of life. In terms of ICF, MERLIN seemed to result in long term improvements in the body functions domain, but not yet on activity or participation level. Future studies should investigate the effect of different training programs including short high dose or continuous low dose treatments. Finally, a RCT is necessary to strengthen our results.

\section{Appendix}

Results of all outcome measures for all measurement times during the MERLIN study $(\mathrm{N}=11)$

\begin{tabular}{|c|c|c|c|c|c|c|}
\hline \multirow[t]{2}{*}{ Outcome measures } & \multicolumn{5}{|l|}{ Mean $\pm S D$} & \multirow{2}{*}{$\begin{array}{l}\text { Post hoc analysis } \\
\text { p-value }\end{array}$} \\
\hline & TO & $\mathrm{T} 1$ & $\mathrm{~T} 2$ & T3 & $\mathrm{T} 4$ & \\
\hline WMFT FAS & $49.0 \pm 10.3$ & $50.6 \pm 11.9$ & $54.4 \pm 11.8$ & $54.8 \pm 13.8$ & $51.5 \pm 13.0$ & $\begin{array}{l}\mathrm{T} 0-\mathrm{T} 2=0.025 \\
\mathrm{~T} 1-\mathrm{T} 3=0.048\end{array}$ \\
\hline WMFT Time & $1.9 \pm 0.4$ & $2.2 \pm 0.6$ & $2.0 \pm 0.5$ & $2.0 \pm 0.4$ & $1.7 \pm 0.3$ & \\
\hline FMA-UE Total & $37.2 \pm 7.6$ & $38.9 \pm 8.6$ & $44.8 \pm 10.1$ & $46.5 \pm 9.9$ & $42.7 \pm 9.3$ & $\begin{array}{l}\mathrm{T} 0-\mathrm{T} 2=0.020 \\
\mathrm{~T} 0-\mathrm{T} 3=0.001 \\
\mathrm{~T} 0-\mathrm{T} 4=0.016 \\
\mathrm{~T} 1-\mathrm{T} 2=0.042 \\
\mathrm{~T} 1-\mathrm{T} 3=0.001\end{array}$ \\
\hline FMA-UE Shoulder & $21.8 \pm 3.9$ & $22.5 \pm 4.0$ & $25.6 \pm 5.4$ & $26.7 \pm 4.9$ & $24.7 \pm 4.5$ & $\begin{array}{l}\mathrm{T} 0-\mathrm{T} 3=0.012 \\
\mathrm{~T} 0-\mathrm{T} 4=0.029 \\
\mathrm{~T} 1-\mathrm{T} 3<0.001\end{array}$ \\
\hline FMA-UE Wrist & $6.0 \pm 2.8$ & $5.4 \pm 2.0$ & $5.8 \pm 2.4$ & $6.5 \pm 2.4$ & $5.3 \pm 2.1$ & \\
\hline FMA-UE Hand & $6.5 \pm 3.1$ & $7.5 \pm 3.8$ & $8.9 \pm 4.0$ & $8.7 \pm 4.1$ & $8.8 \pm 3.7$ & $\mathrm{~T} 0-\mathrm{T} 2=0.035$ \\
\hline $\begin{array}{l}\text { FMA-UE Coordination/ } \\
\text { speed }\end{array}$ & $2.8 \pm 1.3$ & $3.5 \pm 1.3$ & $4.5 \pm 1.2$ & $4.6 \pm 1.2$ & $3.9 \pm 1.3$ & $\begin{array}{l}\mathrm{T} 0-\mathrm{T} 2=0.007 \\
\mathrm{~T} 0-\mathrm{T} 3=0.007\end{array}$ \\
\hline ARAT & $28.8 \pm 13.1$ & $29.4 \pm 14.7$ & $34.2 \pm 16.5$ & $33.4 \pm 17.3$ & $31.2 \pm 16.3$ & \\
\hline EQ-5D health state & $72.3 \pm 18.4$ & $68.3 \pm 16.9$ & $78.8 \pm 16.7$ & $72.5 \pm 15.9$ & $75.5 \pm 15.7$ & \\
\hline EQ-5DVAS & $0.69 \pm 0.12$ & $0.73 \pm 0.14$ & $0.75 \pm 0.08$ & $0.74 \pm 0.10$ & $0.78 \pm 0.08$ & \\
\hline
\end{tabular}

Repeated measures ANOVA with post hoc analysis. Only significant differences are shown, significant difference $=p<0.05$.

ARAT Action Research Arm Test; EQ-5DEurQoL-5 Dimensions; FASFunctional Ability Scale; FMA-UEFugl-Meyer Assessment - Upper Extremity; SD standard deviation; VASVisual Analogue Scale; WMFTWolf Motor Function Test. TO baseline; T1 pre-intervention; T2 post-intervention; T3 follow-up 6 weeks; T4 follow-up 6 months 


\begin{abstract}
Abbreviations
ARAT: Action research arm test; CIMT: Constraint induced movement therapy; EQ-5D: Euro-Quality of Life-5 Dimensions; FAS: Functional ability scale; FMAUE: Fugl Meyer assessment-upper extremity; ICF: International classification of functioning, disability and health; MCID: Minimal clinically important difference; MDC: Minimal detectable change; MERLIN: HoMEcare aRm rehabiLItatioN: MIME: Mirror image movement enabler; SD: Standard deviation; T-WREX: Therapy Wilmington robotic exoskeleton; UMCG: University Medical Center Groningen; VAS: Visual analogue scale; WMFT: Wolf motor function test.
\end{abstract}

\section{Acknowledgements}

The authors would like to thank all participants that dedicated their time and effort to contribute to this research. We would like to thankT. Lutjeboer for his assistance in the project.

\section{Authors' contributions}

SGR, JMH and CKvdS designed the study. SGR conducted the research and performed data analysis. SGR, JMH and CKvdS contributed to writing the manuscript. All authors have read and approved the manuscript.

\section{Funding}

This research was funded by Stichting Beatrixoord Noord-Nederland (Grant No.: 210.183) and EIT Health MERLIN project (Grant No.:19094). EIT Health is supported by the European Institute of Innovation and Technology (EIT), a body of the European Union receives support from the European Union's Horizon 2020 Research and innovation program.

\section{Availability of data and materials}

The dataset supporting the conclusions of this article are available via DataverseNL: https://doi.org/10.34894/MBABRA.

\section{Declarations}

\section{Ethics approval and consent to participate}

All patients signed an informed consent before participating in the study. The study was approved by the local Medical Ethics Committee of the University Medical Center Groningen (UMCG) (METc 2019/189). The competent authority was also informed about the research (Inspection of Healthcare and Youth).

\section{Consent for publication}

Not applicable. The picture of a man training (Fig. 1 and cover page) was made for marketing purpose and was not a participating patient.

\section{Competing interests}

No conflict of interest to report.

Received: 30 April 2021 Accepted: 1 September 2021

Published online: 19 September 2021

\section{References}

1. Bonita R, Beaglehole R. Recovery of motor function after stroke. Stroke. 1988;19:1497-500. https://doi.org/10.1002/dev.20508.

2. Kwakkel G, Kollen BJ, van der Grond J, Prevo AJH. Probability of regaining dexterity in the flaccid upper limb. Stroke. 2003;34:2181-6. https://doi. org/10.1161/01.STR.0000087172.16305.CD

3. Nakayama H, Jorgensen HS, Raaschou HO, Olsen TS. Recovery of upper extremity function in stroke patients. Arch Phys Med Rehabil. 1994;75:394-8. https://doi.org/10.1097/01253086-199519010-00028.

4. Page SJ, Gater DR, Bach-Y-Rita P. Reconsidering the motor recovery plateau in stroke rehabilitation. Arch Phys Med Rehabil. 2004;85:1377-81. https://doi.org/10.1016/j.apmr.2003.12.031.

5. Teasell R, Mehta S, Pereira S, Mclntyre A, Janzen S, Allen L, et al. Time to rethink long-term rehabilitation management of stroke patients. Top Stroke Rehabil. 2012;19:457-62. https://doi.org/10.1310/tsr1906-457.

6. Barker RN, Brauer SG. Upper limb recovery after stroke: the stroke survivors' perspective. Disabil Rehabil. 2005;27:1213-23. https://doi.org/10. 1080/09638280500075717.
7. Lohse KR, Lang CE, Boyd LA. Is more better? Using metadata to explore dose-response relationships in stroke rehabilitation. Stroke. 2014;45:2053-8. https://doi.org/10.1161/STROKEAHA.114.004695.

8. Norouzi-Gheidari N, Archambault PS, Fung J. Effects of robot-assisted therapy on stroke rehabilitation in upper limbs: Systematic review and meta-analysis of the literature. J Rehabil Res Dev. 2012;49:479. https:// doi.org/10.1682/JRRD.2010.10.0210.

9. Veerbeek JM, Langbroek-Amersfoort AC, Van Wegen EEH, Meskers CGM, Kwakkel G. Effects of robot-assisted therapy for the upper limb after stroke: a systematic review and meta-analysis. Neurorehabil Neural Repair. 2017;31:107-21. https://doi.org/10.1177/1545968316666957.

10. Bertani R, Melegari C, De Cola MC, Bramanti A, Bramanti P, Calabro RS. Effects of robot-assisted upper limb rehabilitation in stroke patients: a systematic review with meta-analysis. Neurol Sci. 2017;38:1561-9. https://doi.org/10.1007/s10072-017-2995-5.

11. Mehrholz J, Hädrich A, Platz T, Kugler J, Pohl M. Electromechanical and robot-assisted arm training for improving generic activities of daily living, arm function, and arm muscle strength after stroke. Cochrane Database Syst Rev. 2012. https://doi.org/10.1002/14651858.CD006876. pub3.

12. Kwakkel G, Kollen BJ, Krebs HI. Effects of robot-assisted therapy on upper limb recovery after stroke: a systematic review. Neurorehabil Neural Repair. 2008;22:111-21. https://doi.org/10.1177/1545968307 305457.

13. Lo AC, Guarino PD, Richards LG, Haselkorn JK, Wittenberg GF, Federman DG, et al. Robot-assisted therapy for long-term upper-limb impairment after stroke. N Engl J Med. 2010;362:1772-83. https://doi.org/10.1056/ NEJMoa0911341.

14. Housman SJ, Otr L, Scott KM, Reinkensmeyer DJ. A Randomized controlled trial of gravity-supported, computer-enhanced arm exercise for individuals with severe hemiparesis. Neurorehabil Neural Repair. 2009;23:505-14.

15. Lum PS, Burgar CG, Shor PC, Majmundar M. Robot-assisted movement training compared with conventional therapy techniques for the rehabilitation of upper-limb motor function after. Stroke. 2002;83:952-9. https:// doi.org/10.1053/apmr.2001.33101.

16. Rozevink SG, van der Sluis CK, Garzo A, Keller T, Hijmans JM. hoMEcare aRm rehabiLItatioN (MERLIN): Telerehabilitation using an unactuated device based on serious games improves the upper limb function in chronic stroke. J NeuroEngineering Rehabil. 2021;18:1-12. https://doi. org/10.1186/s12984-021-00841-3.

17. Wolf SL, Winstein CJ, Miller JP, Taub E, Morris D, Giuliani C, et al. Effect of constraint-induced movement therapy on upper extremity function 3 to 9 months after stroke: the EXCITE randomized clinical trial. j Am Med Assoc. 2006;296:2095-104.

18. Kwakkel G, Veerbeek JM, van Wegen EEH, Wolf SL. Constraint-induced movement therapy after stroke. Lancet Neurol. 2015;14:224-34. https:// doi.org/10.1016/S1474-4422(14)70160-7.

19. Hubbard IJ, Parsons MW, Neilson C, Carey LM. Task-specific training: evidence for and translation to clinical practice. Occup Ther Int 2009;16:175-89. https://doi.org/10.1002/oti.

20. World Health Organization. International Classification of Functioning, Disability and Health (ICF). Geneva: World Health Organization; 2011.

21. Lin J-H, Hsu M-J, Sheu C-F, Wu T-S, Lin R-T, Chen C-H, et al. Psychometric comparisons of 4 measures for assessing upper-extremity function in people with stroke. Phys Ther. 2009;89:840-50. https://doi.org/10.2522/ ptj.20080285.

22. Wolf SL, Catlin PA, Ellis M, Archer AL, Morgan B, Piacentino A. Assessing Wolf Motor Function Test as outcome measure for research in patients after stroke. Stroke. 2001;32:1635-9. https://doi.org/10.1161/01.STR.32.7. 1635.

23. Fugl-Meyer AR, Jääskö L, Leyman I, Olsson S, Steglind S. The post-stroke hemiplegic patient. 1. A method for evaluation of physical performance. Scand J Rehabil Med. 1975;7:13-31.

24. Yozbatiran N, Der-Yeghiaian L, Cramer SC. A standardized approach to performing the action research arm test. Neurorehabil Neural Repair. 2008;22:78-90. https://doi.org/10.1177/1545968307305353.

25. Lin K, Hsieh Y, Wu C, Chen C, Jang Y, Liu J. Minimal detectable change and clinically important difference of the wolf motor. Neurorehabil Neural Repair. 2009;19:429-34. 
26. Page SJ, Fulk GD, Boyne P. Clinically important differences for the upperextremity Fugl-Meyer Scale in people with minimal to moderate impairment due to chronic stroke. Phys Ther. 2012;92:791-8. https://doi.org/10. 2522/ptj.20110009.

27. van der Lee JH, Beckerman H, Lankhorst GJ, Bouter LM. The responsiveness of the action research arm test and the Fugl-Meyer assessment scale in chronic stroke patients. J Rehabil Med. 2001;33:110-3.

28. Chen P, Lin KC, Liing RJ, Wu CY, Chen CL, Chang KC. Validity, responsiveness, and minimal clinically important difference of EQ-5D-5L in stroke patients undergoing rehabilitation. Qual Life Res. 2016;25:1585-96. https://doi.org/10.1007/s11136-015-1196-z.

29. Harris PA, Taylor R, Minor BL, Elliott V, Fernandez M, Neal LO, et al. The REDCap consortium: building an international community of software platform partners. J Biomed Inform. 2019. https://doi.org/10.1016/j.jbi. 2019.103208.

30. Harris P, Taylor R, Thielk R, Payne J, Gonzalez N, Conde J. Research electronic data capture (REDCap) - a metadata-driven methodology and workflow process for providing translational research informatics support. J Biomed Inform. 2009;42:377-81.

31. Waddell KJ, Strube MJ, Bailey RR, Klaesner JW, Birkenmeier RL, Dromerick AW, et al. Does task-specific training improve upper limb performance in daily life poststroke? Neurorehabil Neural Repair. 2017;31:290-300. https://doi.org/10.1177/1545968316680493.
32. Krakauer JW. Motor learning: its relevance to stroke recovery and neurorehabilitation. Curr Opin Neurol. 2006;19:84-90.

33. Lo AC, Guarino PD, Richards LG, Haselkorn JK, Wittenberg GF, Federman DG, et al. Robot-assisted therapy for long-term upper-limb impairment after stroke. New Engl J Med. 2010;362(19):1772-83.

34. Lin K, Hsieh Y, Wu C, Chen C, Jang Y, Liu J. Minimal detectable change and clinically important difference of the wolf motor funtion test in stroke patients. Neurorehabil Neural Repair. 2009;23:429-34.

35. Raghavan P. Upper limb motor impairment post stroke. Phys Med Rehabil Clin N Am. 2016;26:599-610. https://doi.org/10.1016/j.pmr.2015.06.008.

36. Ward NS, Brander F, Kelly K. Intensive upper limb neurorehabilitation in chronic stroke: outcomes from the Queen Square programme. J Neurol Neurosurg Psychiatry. 2019;90:498-506. https://doi.org/10.1136/ jnnp-2018-319954.

37. Sale P, Franceschini M, Mazzoleni S, Palma E, Agosti M, Posteraro F. Effects of upper limb robot-assisted therapy on motor recovery in subacute stroke patients. J Neuroeng Rehabil. 2014;11:1-8. https://doi.org/10.1186/ 1743-0003-11-104.

\section{Publisher's Note}

Springer Nature remains neutral with regard to jurisdictional claims in published maps and institutional affiliations.
Ready to submit your research? Choose BMC and benefit from:

- fast, convenient online submission

- thorough peer review by experienced researchers in your field

- rapid publication on acceptance

- support for research data, including large and complex data types

- gold Open Access which fosters wider collaboration and increased citations

- maximum visibility for your research: over $100 \mathrm{M}$ website views per year

At BMC, research is always in progress.

Learn more biomedcentral.com/submissions 